\title{
The IAU and Solar Eclipses
}

\author{
Jay M. Pasachoff ${ }^{1}$, Eijiro Hiei ${ }^{2}$ and Cielo Perez ${ }^{1}$ \\ ${ }^{1}$ Williams College, Williamstown, Massachusetts 01267, USA \\ email: jay.m.pasachoff@williams.edu \\ ${ }^{2}$ National Astronomical Observatory of Japan, Mitaka, Tokyo, Japan
}

\begin{abstract}
We describe the history of solar-eclipse supervision since the formation of the International Astronomical Union, as the supervising body morphed from a full commission to a subcommission to its current status as an Inter-Divisional Working Group of the Education, Outreach and Heritage Division and the Sun and Heliosphere Division.
\end{abstract}

Keywords. solar eclipses, the Sun

\section{Introduction}

Discussions about solar eclipses were made at the first General Assembly of the IAU held at Rome in May 1922, with C13: Commission des expéditions astronomiques, éclipses, etc., with M. le Comte A. de la Baume-Pluvinel, Paris as the President. The President recommended that Committee No.13 be discontinued, and that was agreed to. There was no description on the solar eclipses in IAU Transactions of the 2nd General Assembly of the IAU held at Cambridge, UK, in July 1925. The discussions on solar eclipses internationally were first made at the third General Assembly of IAU held at Leiden in July 1928 under the President of Commission 12, Dr. C.E. St John, who opened the discussion on the report concerning the observation of solar eclipses. Prof. Stratton addressed the formation of the Eclipse Centre of the Solar Physics Commission. At the fourth General Assembly of the IAU held at Cambridge, Massachusetts, USA, in September 1932, President Dr. C.E. St John proposed the reorganization of Solar Eclipses and Solar Physics, etc., and Prof. Stratton addressed the coming eclipses and eclipse problems, see Table 1 . We maintain a website with useful eclipse information at www.eclipses.info.

\section{Recent past and near future eclipses}

We summarize the activities of the IAU Working Group on Solar Eclipses, now an InterDivisional Working Group of Divisions C (Education, Outreach and Heritage) and E (Sun and Heliosphere) over the last triennium and with plans for the next triennium. Since the previous IAU General Assembly, we have had total solar eclipses in Indonesia/Pacific in 2016 and in the United States in 2017, the latter especially with major international participation from groups headed by members of the Working Group and from others. There were annular eclipses that crossed Africa and Indian Ocean islands such as Réunion in 2016 and that crossed Chile and Argentina, reaching Africa, in 2017.

Our Working Group's Website at www.eclipses.info provides much information, including maps and links, suitable for professional astronomers and others.

After an Antarctic and southern Africa partial eclipse in 2017, 2018 included partial eclipses in Argentina/Chile on February 15; Antarctica/Tasmania on July 13; and in the Arctic including northern Scandinavia and previous totality sites at Novosibirsk and in Siberia in Russia (site of 2008 totality) and at Svalbard (site of 2015 totality) 


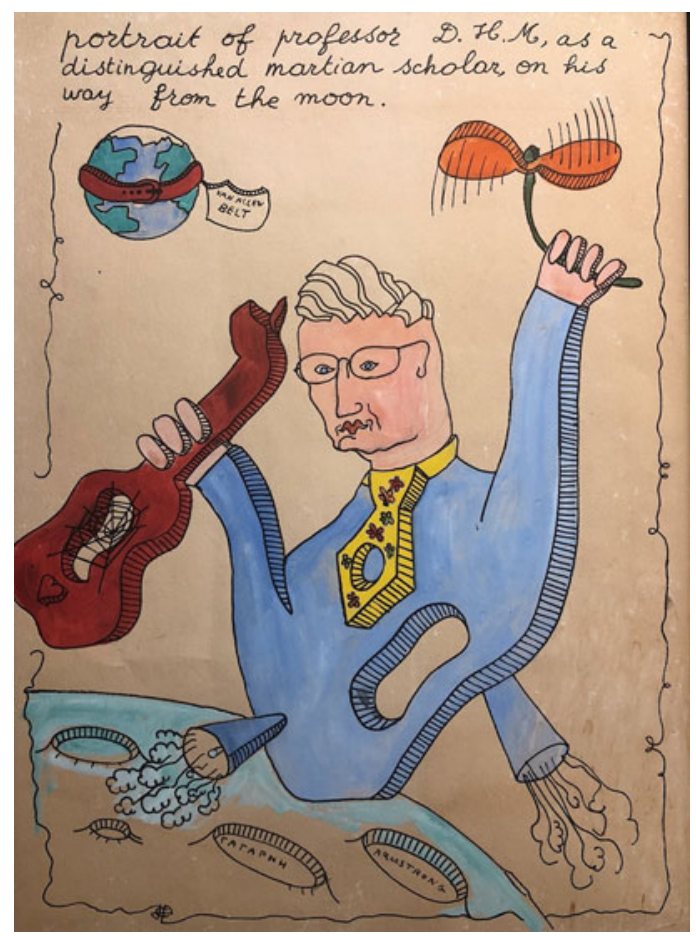

Figure 1. One of D. H. Menzel's self-portraits. He was President of the Commission on Solar Eclipses in Dublin in 1955.

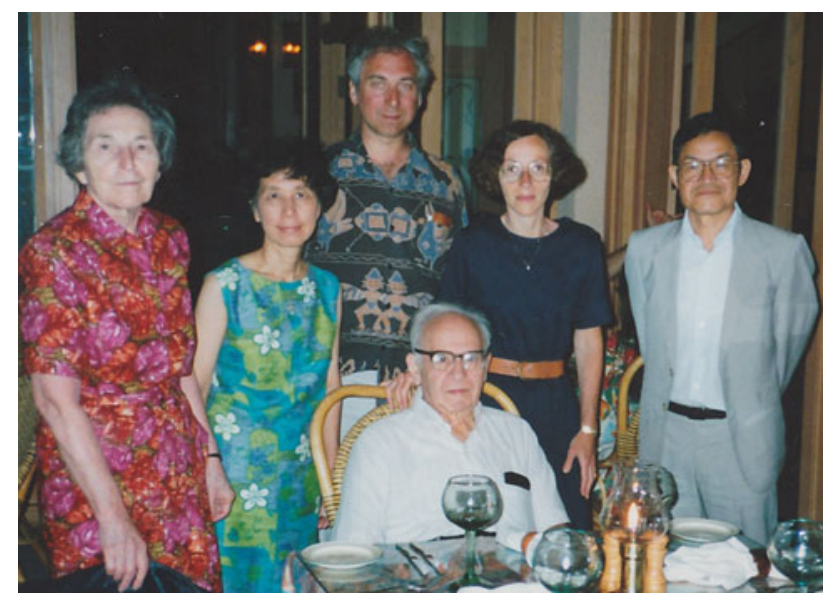

Figure 2. Hieis and Pasachoffs on the occasion of the 1991 total solar eclipse in Hawaii. Left to right: Anna Schwartz, Yumiko Hiei, Jay Pasachoff (Chair 1991-present), Isaac Schwartz, Naomi Pasachoff, Eijiro Hiei (Chair 1985-1991). The Schwartzes were Naomi Pasachoff's parents.

on August 11, 2019 had a partial solar eclipse in eastern Asia on January 5/6, visible from China, Russian Siberia, Korea and Japan.

We have assisted with vouching for our scientists to obtain visas and duty-free temporary import of scientific equipment. Astronomers Without Borders has pre-used gratis partial-eclipse glasses that are available for distribution at future sites where partial, annular or total eclipses are to be visible.

We provided articles summarizing the scientific value of eclipse research (Golub \& Pasachoff 2010, 2014, 2017, Pasachoff 2017, 2018a) and outreach (Pasachoff \& Fraknoi 
Table 1. List of Commission \& Working Group Meetings and Presidents/Chairs

\begin{tabular}{llllr}
\hline GA & Year & Place & President/Chair & Note \\
\hline I & 1922 & Rome & A. de la Baume-Pluvinel & 1 \\
II & 1925 & Cambridge, UK & C.E. St. John & 1 \\
III & 1928 & Leiden & C.E. St. John & 1 \\
IV & 1932 & Cambridge, MA & C.E. St. John & 1 \\
V & 1935 & Paris & F.J.M. Stratton & 1 \\
VI & 1938 & Stockholm & S.A. Mitchell & 2 \\
VII & 1948 & Zurich & S.A. Mitchell & 2 \\
VIII & 1952 & Rome & S.A. Mitchell & 2 \\
IX & 1955 & Dublin & D.H. Menzel & 2 \\
X & 1958 & Moscow & R.O. Redman & 2 \\
XI & 1961 & Berkeley, CA & R.O. Redman & 3 \\
XII & 1964 & Hamburg & J. Houtgast & 4 \\
XIII & 1967 & Prague & J. Houtgast & 4 \\
XIV & 1970 & Brighton & M. Rigutti & 4 \\
XV & 1973 & Sydney & G. Newkirk & 4 \\
XVI & 1976 & Grenoble & G. Newkirk & 4 \\
XVII & 1979 & Montreal & J.L. Leroy & 4 \\
XVIII & 1982 & Patras & J.L. Leroy & 4 \\
XIX & 1985 & Delhi & E. Hiei & 4 \\
XX & 1988 & Baltimore & E. Hiei & 4 \\
XXI & 1991 & Buenos Aires & J.M. Pasachoff & 4 \\
XXII & 1994 & The Hague & J.M. Pasachoff & 4 \\
XXIII & 1997 & Kyoto & J.M. Pasachoff & 4 \\
XXIV & 2000 & Manchester & J.M. Pasachoff & 4 \\
XXV & 2003 & Sydney & J.M. Pasachoff & 4 \\
XXVI & 2006 & Prague & J.M. Pasachoff & 4 \\
XXVII & 2009 & Rio de Janeiro & J.M. Pasachoff & 4 \\
XXVIII & 2012 & Beijing & J.M. Pasachoff & J.M. Pasachoff \\
XXIX & 2015 & Honolulu, HI & J.M. Pasachoff & 4 \\
XXX & 2018 & Vienna & Cora & 4 \\
\hline Xotes: & & & 4 & 4 \\
\hline
\end{tabular}

Notes: [1] 13. Commission des éclipses solaires; [2] 13. Commission Eclipses of the Sun; [3] 12a. sous-commission des éclipses de soleil; [4] Working Group on Solar Eclipses

Table 2. IAU Working Group on Solar Eclipses: Members (2018)

\begin{tabular}{ll}
\hline Jay Pasachoff & USA, Chair; http://eclipses.info \\
Iraida Kim & Russia \\
Jagdev Singh & India \\
Vojtech Rusin & Slovakia \\
Yoichiro Hanaoka & Japan \\
Zhongquan Qu & China \\
Beatriz García & Argentina \\
Patricio Rojo & Chile \\
Xavier Jubier & France; mapping: http://eclipses.info; http://xjubier.free.fr/en \\
Fred Espenak & USA: http://eclipsewise.com \\
Jay Anderson & Canada; cloudiness and weather statistics: http://eclipsophile.com \\
Glenn Schneider & USA \\
Michael Gill & UK; Solar Eclipse Mailing List: SEML@yahoogroups.com \\
Michael Zeiler & USA; mapping: http://eclipse-maps.com \\
Bill Kramer & USA; statistics: http://eclipse-chasers.com \\
Ralph Chou & Canada; eye safety: https://eclipse.aas.org/eye-safety \\
\hline
\end{tabular}

2017; Pasachoff 2018b; Peticolas et al. 2018). We gathered summaries of recent eclipse results (Pasachoff et al. 2018; Mikic et al. 2018; Hanaoka et al. 2018; Tian et al. 2017) We provided a clearinghouse for methods of observation and data reduction (Druckmüller et al. 2006, e.g.).

The following triennium has total solar eclipses in Chile/Argentina on July 2, 2019, and on December 14, 2020; and annular eclipses on December 26, 2019, June 21, 2020, and June 10, 2021 (Fig. 3).

Our Working Group (Table 2) currently includes members from Russia, Japan, India, Slovakia, China, USA, UK, France, Chile, Argentina and Canada. 


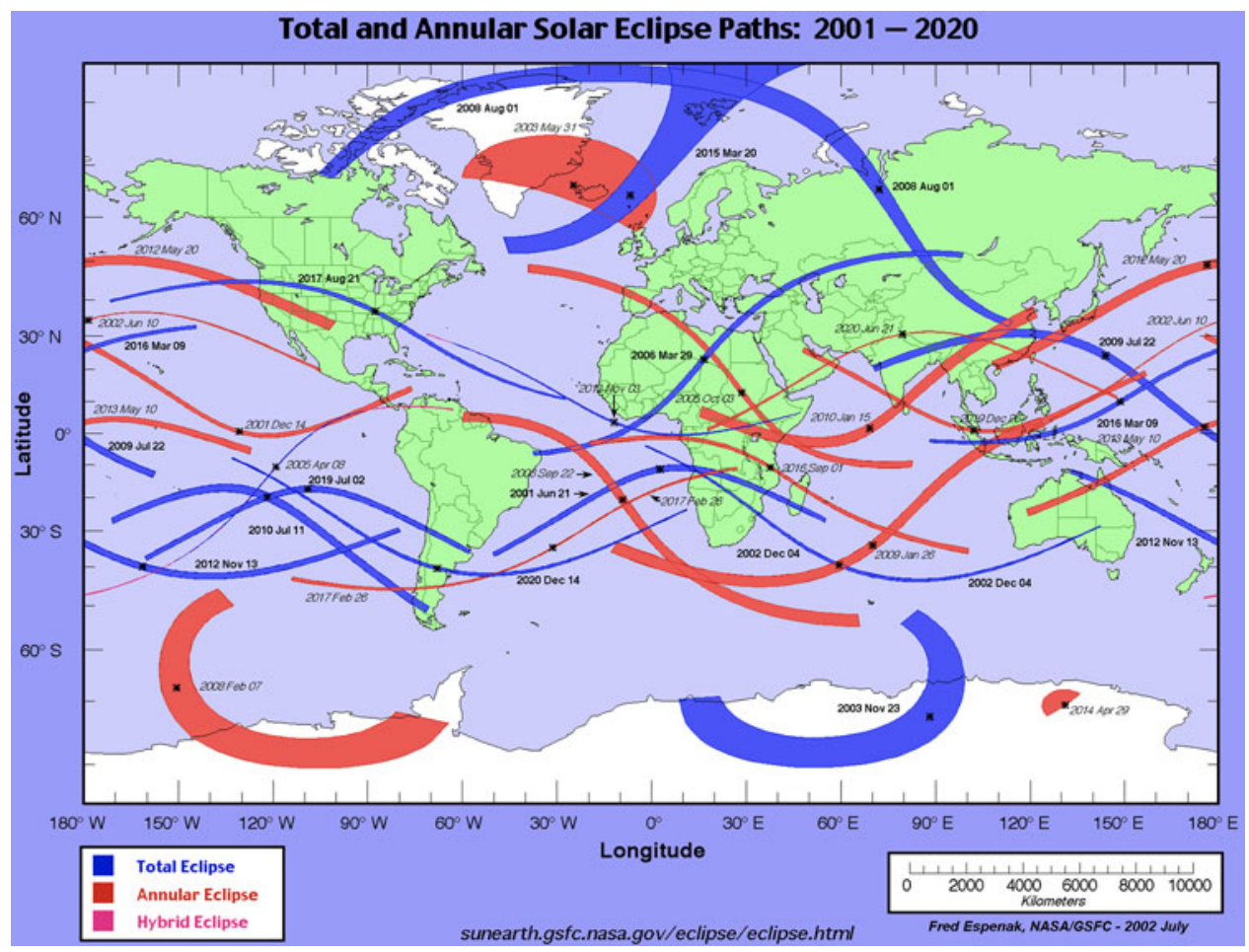

Figure 3. A map of total and annular eclipses during 2001-2020. (Fred Espenak, EclipseWise.com).

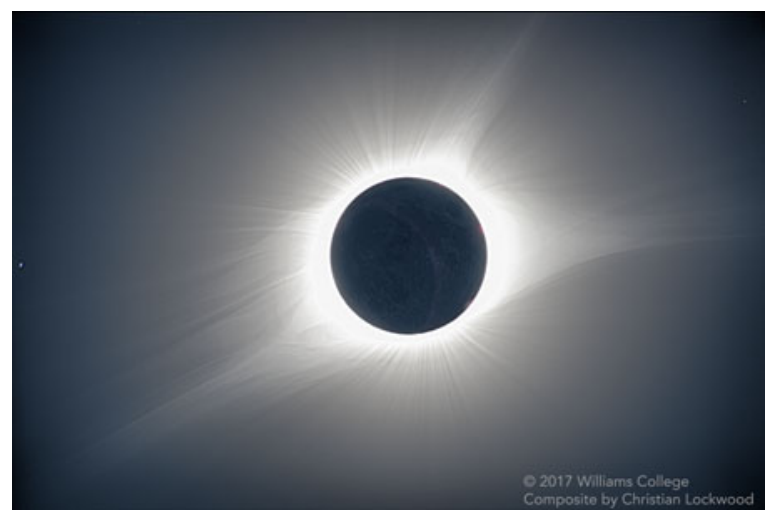

Figure 4. A composite image of the 21 August 2017 total solar eclipse, from the Williams College Solar Eclipse Expedition site in Salem, Oregon, USA.

\section{Acknowledgements}

JMP's eclipse research, including the preparation of this paper, and the Williams College Eclipse Expedition (Fig. 4) were supported largely by grants AGS-1602461 from the Solar Terrestrial Program of the Atmospheric and Geospace Sciences Division of the US National Science Foundation and 9876-16 from the Committee for Research and Exploration of the National Geographic Society. CP was supported in part by the Clare Boothe Luce Foundation grant to Williams College. 


\section{References}

Druckmüller, M., Rusin, V. \& Minarovjech, M. 2006. Contr. Astron. Obs. Skalnaté Pleso 36, 131

Golub, L. \& Pasachoff, J. M. 2010. The Solar Corona, 2nd Edn. (Cambridge, UK: Cambridge Univ. Press)

Golub, L. \& Pasachoff, J. M. 2014, Nearest Star: The Surprising Science of Our Sun. 2nd Edn. (Cambridge, UK: Cambridge Univ. Press)

Golub, L. \& Pasachoff, J. M. 2017 The Sun (London: Reaktion Books)

Hanaoka, Y., Hasuo, R., Hirose, T., Ikeda, A. C., Shibashi, T., Manago, M. et al. (2018). Ap.J., 860:142. doi: 10.3847/1538-4357/aac49b

Mikic, Z., Downs, C., Linker, J. A., Caplan, R. M., Mackay, D., Upton, L., Riley, P., Lionello, R., Török, T., Titov, V., Wijaya, J., Druckmüller, M., Pasachoff, J. M. \& Carlos, W. 2018, Nature Astronomy 2, 913, doi.org/10.1038/s41550-018-0562-5

Pasachoff, J. M. 2017a, Nature Astronomy 1, 0190 (August). www.nature.com/articles/s41550017-0190rdcu.be/uEuz

Pasachoff, J. M., Lockwood, C. A., Meadors, E. N., Yu, R., Perez, C. C., Pealoza-Murillo, M. A., Seaton, D. B., Voulgaris, A., Dantowitz, R. F., Rusin, V. \& Economou, T. E. 2018, in Scott W. McIntosh, Michael Thompson, Chris G. Tzanis, eds., Frontiers in Astronomy and Space Sciences: The Great American Eclipse of August 21, 2017 Connecting Solar and Terrestrial Science, Frontiers Astron. \& Sp. Sci., 5:37. doi: 10.3389/fspas.2018.00037

Pasachoff, J. M. \& Fraknoi, A. 2017, "Resource Letter OSE-1 on Observing Solar Eclipses", Am. J. Phys. 85(7), 485-494, July. https://aapt.scitation.org/doi/pdf/10.1119/1.4985062

Peticolas, L., et al. 2018, in The 2017 Total Solar Eclipse, Astronomical Society of the Pacific Conference Series, S. Buxner, L. Shore \& J. Jensen, eds.

Pasachoff, J. M. 2017, Heliophysics at Total Solar Eclipses, Nature Astronomy 1, article number 0190 (August). www.nature.com/articles/s41550-017-0190rdcu.be/uEuz

Pasachoff, J. M. 2018a, Science at the Great American Eclipse, Astronomy $\&$ Geophysics (A\&G), 59 (August), 4.1-4.5

Pasachoff, J. M. 2018b, Education and Outreach about Science at the 2017 Eclipse, in The 2017 Total Solar Eclipse, Astronomical Society of the Pacific Conference Series, Sanlyn Buxner, Linda Shore, and Joe Jensen, eds.

Tian, H., Qu, Z., Chen, Y., Deng, L., Huang, Z., Li, H., et al. 2017, Earth Planet. Phys. 1, 6871. doi: 10.26464/epp2017010 